\title{
Development and evaluation of an online learning object to improve pre-registration nursing students' knowledge and engagement with pre-operative fasting
}

\section{Stuart Roberts}

Manchester Metropolitan University, UK

\section{Richard Windle}

University of Nottingham, UK

\section{Abstract}

\section{Background}

Having identified a need to improve education around pre-operative fasting, and to facilitate more Technology Enhanced Learning (TEL), an online learning tool was developed.

\section{Design}

An evaluation study was conducted to ascertain the effectiveness of the tool in developing knowledge in a group of pre-registration nursing students.

\section{Results}

A quiz attached to the online teaching tool showed a high level of information uptake, $63 \%$ $(n=44)$ of the students achieved a mark of $90 \%$ or higher and only $15 \%(n=11)$ achieving a mark of less than $70 \%$. A questionnaire was undertaken resulting in the students highlighting their enthusiasm for engagement in similar learning opportunities in the future.

Keywords: Technology Enhanced Learning; evaluation; blended learning; pre-operative fasting; learning objects. 


\section{Introduction}

The knowledge of newly qualified nursing staff regarding pre-operative fasting can be erratic and poorly applied (Chand and Dabbas, 2004; Bothamley and Mardell, 2005; Baril and Portman, 2007; Sutton and Smith, 2008; Crenshaw and Winslow, 2008). Given this is such a fundamental aspect of surgical care (Roberts, 2013), improvements in nursing knowledge should lead to improvements in patient outcomes relating to post-operative nausea and vomiting (PONV), and consequently avoid delayed discharge. It could be posed therefore that the topic matter is a threshold concept, due to the usual necessity to provide nutrition to a patient rather than withhold it, and therefore consideration of alternative ways to teach this to professionals is needed (Meyer and Land, 2005).

Most training around pre-operative fasting is class-based, and whilst face-to-face methods of delivery can be effective and popular with health care students, inclusion of additional online resources in other areas has been shown to enhance the learning experience of the student, as well as increasing knowledge (Rigby et al., 2012). It allows for choice, reinforcement and timely repetition of learning (Johnson et al., 2010). Difficult or threshold concepts, such as starving a patient, need to accommodate diverse approaches to learning such as offered by online resources (Sun and Ganesh, 2014). These approaches should support flexibility and multiple and reiterative pathways, such as; individual learning at own pace, learning which gives instant feedback, hyperlinking to further study, quizzes etc. Moreover, this learning can be supported in a blended way by supporting the student with human interaction and feedback in dialogue that can offer differing explanations until the concept is understood. Therefore, there is scope for development of a well-structured learning tool on pre-operative fasting and an evaluation of its effectiveness.

Whilst online and blended learning have been widely adopted in health care (Williams et al., 2015), including training and information dissemination websites, computer aided learning packages (Wharrad et al., 2010) and simulations and discussion-based activities (Childs et al., 2005), the learning object (LO) format has proved effective and durable; especially for the acquisition of very specific units of training (Ruiz et al., 2009), which is what is being developed here. LOs are small, highly focused packages of e-learning content, each based around a single, well-defined learning outcome. They are usually multimedia in nature and seek to engage the learner in an active learning process through the use of simple interactions and self-testing (Windle and Wharrad, 2010). They have 
been found to be highly valued by healthcare students of differing professions (Gee et al., 2015), especially with respect to the "just in time" nature of the learning, the use of visual learning elements, interactivity, their accessibility and also the extent to which they provide the learner with control over their learning (Wharrad and Windle, 2010). Moreover, this form of learning has been shown to improve learning outcomes in a range of subject areas (AlfredoSanchez et al., 2015). Therefore, we developed an LO which focused upon the threshold concept of fasting patients, allowing students to learn and engage in a selfdirected manner, and followed this a week later with a one hour, blended learning, face-toface session to assess if the concept was understood and to provide further learning opportunities. This was followed by an evaluation study which assessed the student experience of using the LO and the student perception of its usefulness in acquisition of a difficult concept.

\section{Teaching and learning approach and resources}

Many features of online learning are attractive to learners, including interactivity, imagery and further opportunities to learn; all these elements highlight why McCutcheon et al. (2015) found in their systematic review that a number of papers reported a higher level of satisfaction amongst students using online learning in undergraduate nursing programmes. Control of learning is also a key feature, with research showing that the ability of students to take ownership of learning, to work at their own pace and to self-test is mentioned as one of the crucial benefits of e-learning, particularly in relation to LOs (Moeller and Reitzes, 2011).

The LO was developed using existing functionality within the VLE (Virtual Learning Environment, in this case Moodle). It consisted of text-based and multimedia content that was evidence based and discussed the threshold concept of pre-operative fasting (Figure 1), exploring the necessity for it and the consequences of not fulfilling the need for it. Following on from this was a separate online formative quiz that gave instant feedback and signposted students to further learning if required. 


\section{Figure 1. (Screenshot)}

\section{Patient centred and multiprofessional approach}

Ensuring a patient centred approach in nursing is paramount, communication and knowledge around the area of discussion are key to ensuring that patients and carers are informed fully, and allows them to ask question around their care. Information relating to preoperative fasting is usually performed in preoperative assessment prior to being admitted to hospital, but on occasion these intructions might be delivered at the patient bedside. Wherever the instructions are given the patient should be given time to absorb all information relating to fasting with a rationale why it is necessary, and they need to be given opportunity to redress any arising issues or questions they have around the need to fast.

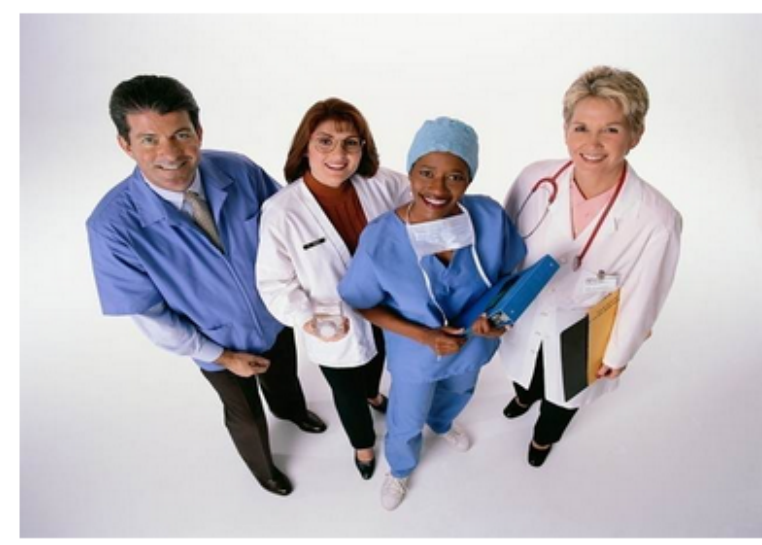

It is necessary to facilitate a multiprofessional approach in the care of patients undergoing surgery. Whilst it may be the nurse delivering the instructions for fasting at a preoperative assessment appointment, input into the indoviduals fasting and/or dietary requirements are going to be closely monitored by the anaesthetist and surgeon also.

Communication within the team caring for the patient is therefore paramount, there is a need to collaborate and deliver the same information to the patient that is relevant to their individual circumstances.

The resource was offered to a cohort of students $(n=98)$ in the second year of a BSc preregistration nursing programme. The deployment of the tool was scheduled to be completed 7 days prior to a taught session delivered in October 2013.

\section{Evaluation methods and analysis}

Students who consented to take part in the study were asked to complete two evaluation instruments. In order to determine whether the resources were effective in supporting student's learning, an online knowledge questionnaire based on the fasting times recommended in national guidelines (RCN, 2005) was delivered via the VLE following completion of the learning tool. Secondly, a paper-based evaluation questionnaire to ascertain students' experience of using the resource was deployed at the end of a subsequent module session. Students were asked to rate different aspects of the resource (such as their views of the online tool and how it might be used in future learning) on a 
Likert Scale, ranging from one (strongly disagree) to five (strongly agree). Content validity of the tools was checked by content specialists, as recommended by Rebar et al. (2011). Face validity of the evaluation questionnaire was checked by four second year undergraduate nursing students from a separate cohort.

This study was conducted in line with the ethics policy of the university in which the evaluation took place. This states that for evaluation, ethical approval should be gained from the programme leader. All data was anonymised and stored in accordance with University guidance on data storage and management.

Data presented are the mean and percentage responses from the group. Where group parameters are presented, they are presented as mode score values. Correlations were conducted using Spearman's rank correlation tests.

\section{Results}

\section{Completion rates}

In total, 70 students consented to take part in the study. This represents $71 \%$ of the study population. Of these 62 students ( 5 males, 47 female, 10 gender withheld) completed the online evaluation questionnaire. The age of participants ranged from 19-47. Figure 2 categorises the age-distribution within the sample and highlights the broad cross-section of ages represented, 11 participants chose to withhold information regarding their age. 


\section{Figure 2.}

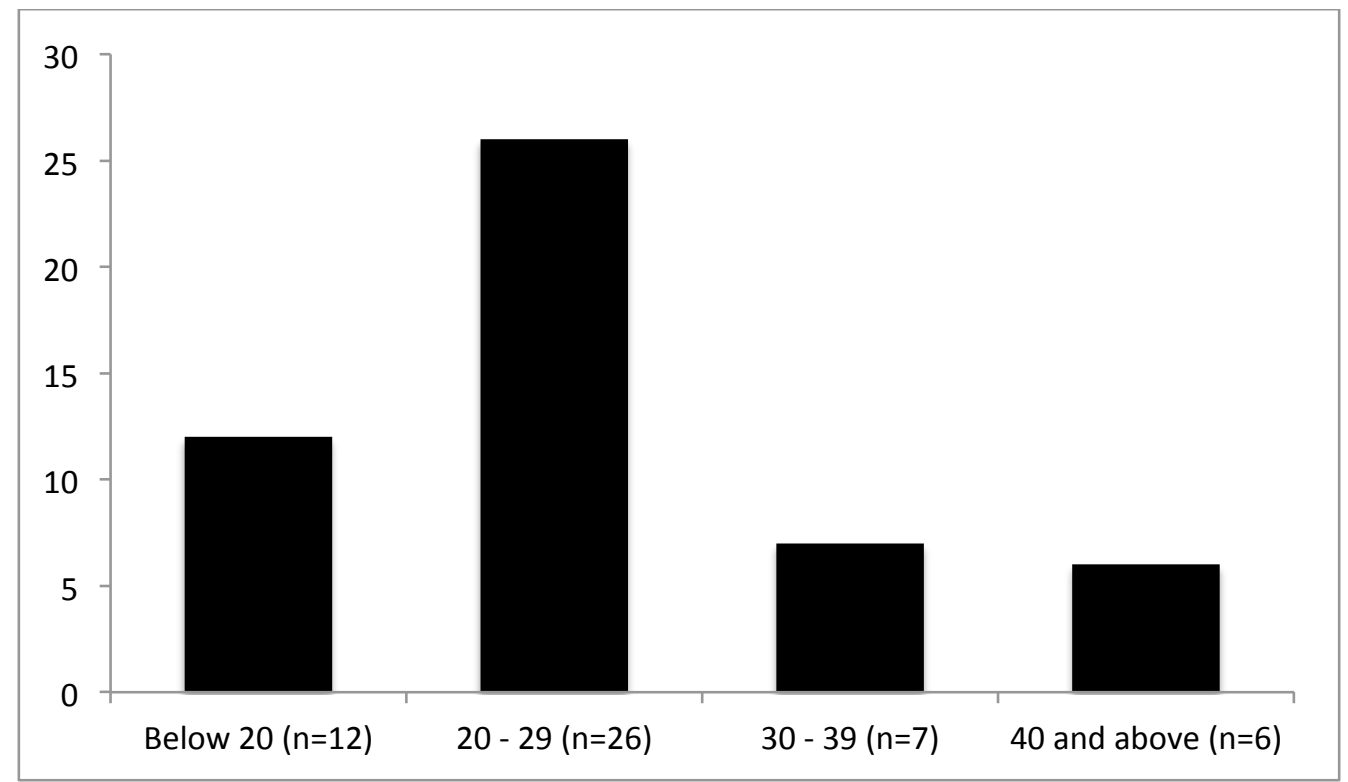

\section{Knowledge assessment}

The majority of students, $63 \%(n=44)$ of the students achieved a mark of $90 \%$ or higher on the summative online test, indicating that after completing the package they had a comprehensive knowledge of pre-operative fasting (Figure 3). Only 15\% ( $n=11)$ achieving a mark of less than $70 \%$. No student achieved a mark of less than $40 \%$ (Figure 3 ). Tracking data showed that students took between 1 min 14 seconds to 27 min 18 seconds to complete the questionnaire. There was no correlation between the time taken and the results gained (data not shown). 


\section{Figure 3.}

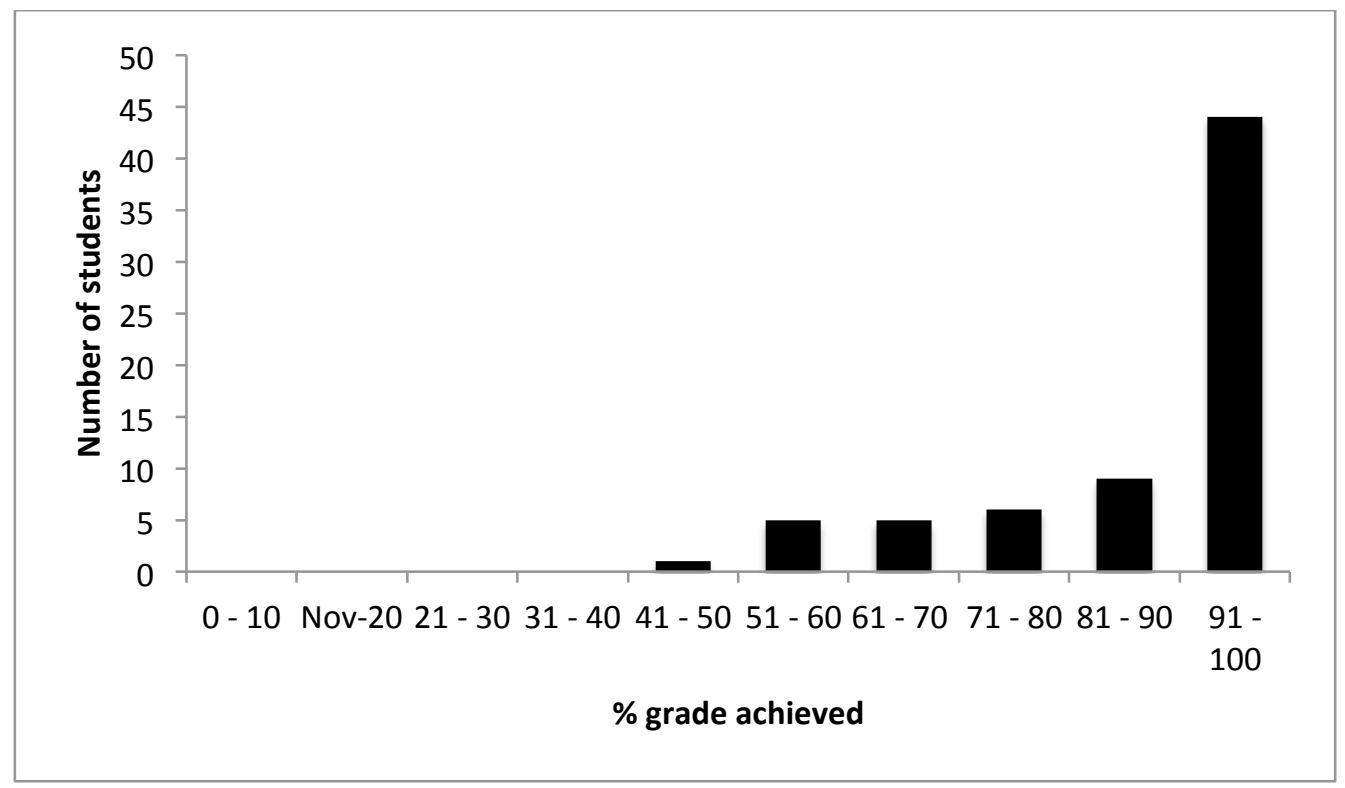

\section{Learning experience}

Exploring their experience and the value of the LO, 90.3\% $(n=56)$ of students either agreed or strongly agreed that the online teaching tool had improved their knowledge in the area of preoperative fasting. While no students disagreed with this statement (see Figure 4A), it may not be seen as an objective measure of knowledge gain but the students saw a perceived value, which is also important in learning and motivation. 85.5\% $(n=53)$ of students either agreed or strongly agreed with the statement: 'I feel this type of online teaching tool enhanced my learning experience', with only one student $(1.6 \%)$ disagreeing (Figure 4B). Students valued the tool as a component of blended learning with $77 \%$ of students agreeing or strongly agreeing with the statement 'I feel the opportunity to follow up the online learning in class was beneficial' (Figure 4C). However $33 \%$ of students $(n=21)$ disagreed or strongly disagreed with the statement 'this format of learning was better than receiving the same information face-to-face', although 53\% ( $n=33)$ strongly agreed or agreed with this statement, suggesting a high level of variation in perceived relative value of this type of learning (Figure 4D). 


\section{Figure 4.}
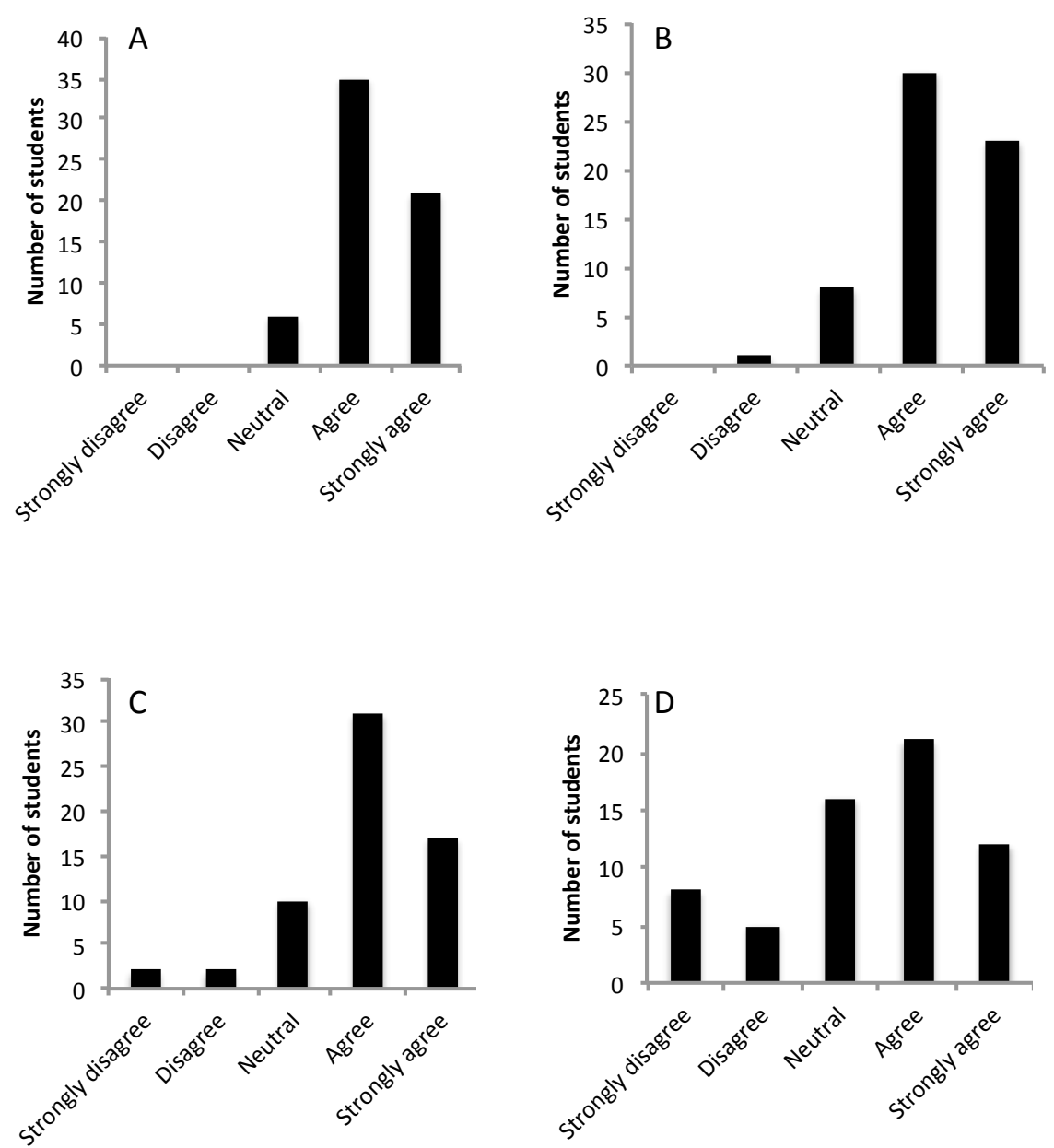

In terms of the wider impact on learning, $70.9 \%$ of students $(n=44)$ strongly agreed or agreed with the statement 'I used the extra resource links to learn more about the subject matter' (Figure 5A). However, a lower proportion of students indicated that the use of the resource had had a wider impact on their confidence to use other aspects of online learning with only $41.9 \%(n=26)$ agreeing or strongly agreeing with the statement 'this online teaching resource has made me more confident in using Moodle' (Figure 5B).

Overall, $86 \%$ of students agreed or strongly agreed that they 'hope to use more online learning resources such as this in the future' (Figure $5 \mathrm{C}$ ). 


\section{Figure 5.}
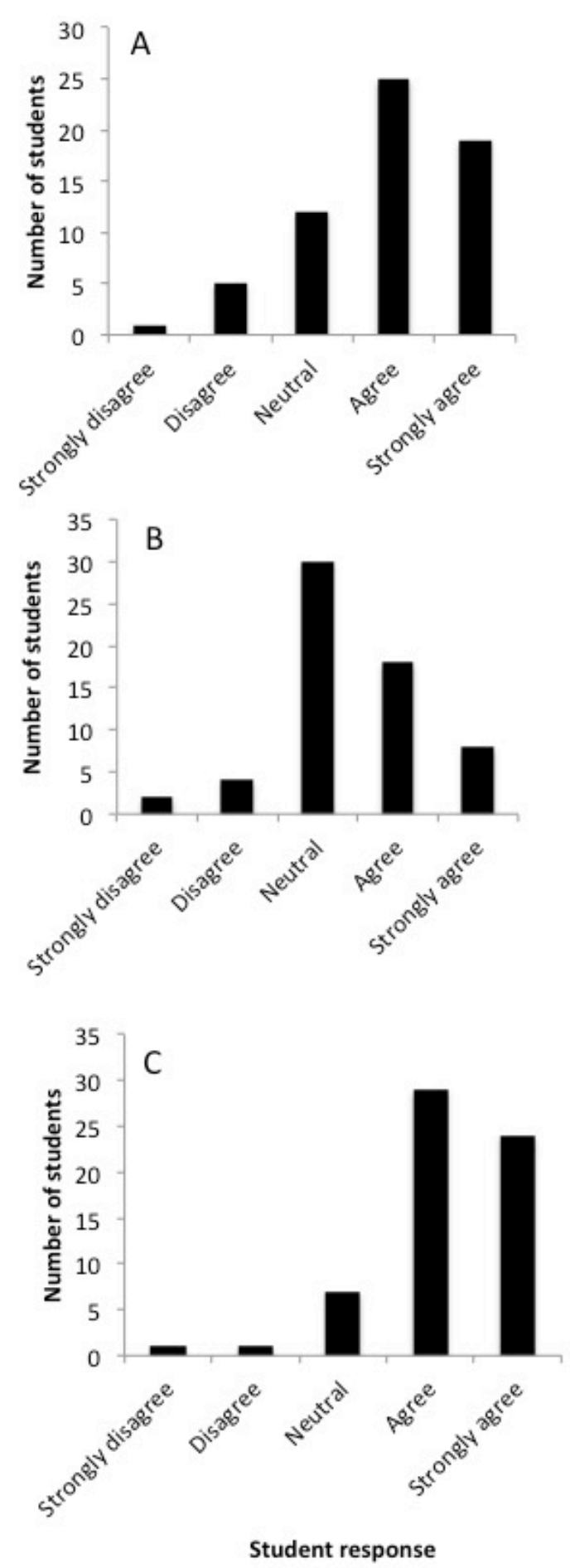

Correlations between questions showed that responses to the statement, 'I feel this type of online teaching tool enhanced my learning experience' and the statement 'I hope to use more online learning resources such as this in the future' were most strongly correlated with $91 \%(n=48)$ of those agreeing or strongly agreeing to statement one also agreeing or strongly agreeing to statement six (coefficient 0.5 ). 


\section{Improvements}

$42 \%$ ( $n=26)$ of the students felt that no improvements needed to be made to the online learning tool, indicating they were happy with how it engaged them and improved their knowledge:

It was great, no problems - particularly liked the links. (Student 1)

A known technical issue that affected the delivery of the resource was commented on by $19 \%(n=12)$ of the students.

Many students $15 \%(n=9)$ wanted increased opportunities to test their own learning:

More questions, related to conflicts around fasting. (Student 2)

Other students $(15 \%, n=9)$ requested improvements to the resources used within the online teaching tool, with suggestions such as inclusion of more visual elements like videos, diagrams or pictures. Three students $(5 \%)$ suggested that online learning should be improved by having more face-to-face lessons alongside it:

Have follow up sessions after the set work. (Student 3)

Two students (3\%) felt the online learning tool would be improved by containing less information.

\section{Barriers to learning}

The majority of students $55 \%(n=34)$ felt that there was no reason why they would not participate in the use of LOs in the future by answering either "no" or "none". A further $21 \%$ $(n=13)$ left this answer blank. However, the below issues were raised:

If time limits or attempt limits were placed on access $8 \%(n=5)$ :

No second attempt would discourage my future participation. (Student 4) 
Preferring face to face input $(6 \%, n=4)$ :

No substitute for lectures. (Student 5)

Not being able to ask questions $(3 \% n=2)$ :

Face-to-face affords better opportunities to ask questions. (Student 6)

If too much information were included:

If there were more questions I might not remember all of the information. (Student 7)

A lack of feedback $(2 \% n=1)$ :

If I am not able to know which ones I got right or wrong. (Student 8)

\section{Future uses}

Students were able to articulate suggestions for other areas of the curriculum that could be covered by LOs. These are summarised in Table 1. The largest single subject area identified was anatomy and physiology, whilst smaller groups of students suggested areas such as clinical or pharmacology.

Many students indicated that all or most subjects would be suitably covered with comments such as:

All subjects should use the online tool. (Student 9)

All (subjects) could benefit, easy tool to use and good for reference. (Student 10)

Only $21 \%(n=13)$ of students failed to suggest which other subjects they would like to see adopt this kind of teaching format. 
Table 1.

\begin{tabular}{|l|l|}
\hline Suggested subjects & Number of students \\
\hline All subjects & $20(32 \%)$ \\
\hline Most subjects & $4(6 \%)$ \\
\hline Anatomy and Physiology & $21(33 \%)$ \\
\hline Clinical Skills & $4(6 \%)$ \\
\hline Pharmacology & $3(4 \%)$ \\
\hline Mental Health & $1(2 \%)$ \\
\hline Application & $1(2 \%)$ \\
\hline
\end{tabular}

When specifying what further LOs might be used for, the most common theme to arise was their use as a revision or reference tool:

Great also for revision, it certainly helped my knowledge. (Student 11)

Revision on subjects we've already done. (Student 12)

But again, students cautioned against the loss of complementary face-to-face contact:

Not as a complete substitute for face-to-face learning. (Student 13)

\section{Discussion}

\section{Knowledge and learning}

The results of this study show that all students had acquired a good knowledge of preoperative fasting after completion of the resource, with the vast majority able to answer over $90 \%$ of the online test correctly. This is in line with other studies that have shown significant increases in "actual" knowledge or attainment in relation to LO usage, including 
those that have shown a significant increase in modular results after the introduction of LOs (Farha, 2009; Windle et al., 2010) or have shown effects more experimentally using pre and post testing (Gauss and Urbas, 2003; Costelloe et al., 2009; Halverson et al., 2009). This also supports the theory in the introduction that imparting knowledge of threshold concepts such as this topic, using both online and blended learning, enhances the uptake of knowledge (Meyer and Land, 2005). To use online learning without blended learning would not fully allow us to gauge student understanding, whereas during a faceto-face session academics are able to have dialogue and use discursive methods to engage students to share ideas and make visible their conceptualisations.

Whilst it is not possible to show a definitive increase in knowledge in this study, all students in this study felt that use of the resource had improved their knowledge. This again, is consistent with the literature in the area, where a number of studies have shown self-reported increases in knowledge with the use of such resources (Macdonald 2005; Conceição et al., 2006; Cochrane, 2007; Lymn et al., 2008). However, consideration needs to be given to perceived knowledge versus actual knowledge, something that is highlighted as an issue in e-learning by Ghoncheh et al. (2014) who considered the effectiveness of e-learning to improve knowledge on 154 participants during a randomised controlled trial. There is also evidence to show a correlation between self-reported knowledge and measured knowledge. Therefore, it is likely that the perceived increase in knowledge recorded by the students in the current study is consistent with an actual increase in knowledge.

\section{Reflection}

\section{Pedagogic theory}

Teaching styles as well as dimensions of knowledge need consideration alongside each other within online learning. Hughes and Quinn (2013) discuss the different styles used specifically within nurse education, their main focus being cognitive styles. They explain how Kolb (1984) identified four styles of learner (converger, diverger, assimilator, accommodator) referring to the differing ways in which learners assimilate information. While Honey and Mumford (2000) alternatively describe a cycle of learning (experiencing, reviewing, concluding, planning) that incorporates a number of learning style characteristics (activist, reflector, theorist, pragmatist). Pedagogic theory must be reflected 
upon when implementing online learning to ensure a blended approach is taken, invariably meeting more students' learning styles.

The resources used in this study were delivered in combination with face-to-face training and this allowed evaluation of the role the resources could play in this blended situation. Overall students were very positive about the fact that the LO had enhanced their learning experience, and most felt that this was a valuable opportunity to follow up on face-to-face learning. It is worth noting that the over half of the students agreed or strongly agreed with the statement that the online format was better than receiving the same information faceto-face. However, a large number of students were either neutral or disagreed with this statement, suggesting a high degree of variability in preferred learning styles. This theme does recur a number of times throughout many of the students' responses, calling for a balance between face-to-face teaching and online learning. When considering this feedback it is worth noting that Wakefield et al. (2008) recommend that whichever learning mode is to be used, that this is made explicit to the learner. The intention of this study was not to replace face-to-face learning but to introduce new ways of learning alongside existing ones to better cater to differing learning styles, something which Rigby et al. (2012) identified as being the most acceptable and effective way of delivering education, and Sung et al. (2008) recommend within nursing programmes. As well as this design strength, by incorporating activities such as the online formative quiz feedback, students were able to reflect and undertake further study prior to their classroom engagement, therefore enhancing the face-to-face interaction. It might have been possible to fully meet the needs of a wider range of learners if other aspects of online learning, such as discussion forums had also been included.

\section{Limitations of the study}

The main limitation of the study protocol was the fact that no control group was used Macnee and McCabe (2008). However, to implement such a group could have raised ethical issues, as there would have been an educational process denied to some of the students even though they could have been given access once the study was complete. In this study protocol it was not possible to correlate the responses of the knowledge quiz with the evaluation questionnaire and therefore it was not possible to look at potential 
correlations between these factors. This might have shed light on the reasons for results found.

A 'pretest-posttest' design study would be able to establish if the tool enhanced knowledge around pre-operative fasting; Melnyk and Fineout-Overholt (2011) and Rebar et al. (2011) highlight the benefit of establishing a pre-test to highlight the benefits of an intervention. If found to be effective, other tools could be developed in nurse education that research highlights are problematic in relation to patient safety, or could benefit from an extra focus. The LO could also be recommended and disseminated to other institutions and a study be undertaken to consider evaluating on a wider audience. This would allow for correlation and comparisons to this study. The reason a 'pretest-posttest' was not performed on this evaluation study was due to the fear of over assessing the students unnecessarily.

\section{Wider implications}

Although students had previously interacted with Moodle they had not engaged with a Moodle book application, which is how this LO was designed (see Figure 1). Feedback from the students showed that they enjoyed this type of interaction and that they would be confident in using this method of learning again in the future. Supporting this further, the vast majority of the students hoped to use more online learning resources in the future. Whilst this does not reflect the type of reuse discussed by Windle et al. (2010), which looked at cross-institutional use, the LO has potential to be available and used by other undergraduate students on the course. This facilitates the student as a change agent, giving them the ability to learn at their own pace and creating an adaptable curriculum.

As previously highlighted in Table 1, this type of learning tool could be implemented to encompass a number of subject areas in nurse education. As well as subject areas that the students highlighted such as Anatomy and Physiology (A\&P) which have been widely implemented by other Higher Education Institutions (HEIs), other topics could be developed into LOs such as nursing theories and research methods and be contained within a VLE. McVicar et al. (2014) report success in this type of delivery, specifically with year one pre-registration nursing students on the topic of biosciences. 


\section{Conclusion}

This evaluation study has shown that the development of online learning through LOs can be well received by students as part of a blended learning approach and can help to support a high degree of knowledge acquisition. Future consideration needs to be given to other topics, which could be seen as threshold concepts, to develop alternative means of delivery such as those evaluated here. LOs need to be considered as an alternative way of learning where current pedagogical theories are not meeting learner requirements.

\section{References}

AlfredoSanchez, J., Perez-Lezama, C. and Starostenko, O. (2015) 'A formal specification for the collaborative development of learning objects', Procedia - Social and Behavioral Sciences, 182, pp. 726-731. https://doi.org/10.1016/j.sbspro.2015.04.820

Baril, P. and Portman, H. (2007) 'Preoperative fasting: knowledge and perceptions', Association of Perioperative Registered Nurses (AORN) Journal, 86(4), pp. 609617. http://dx.doi.org/10.1016/j.aorn.2007.09.003

Bothamley, J. and Mardell, A. (2005) 'Preoperative fasting revisited', British Journal of Perioperative Nursing, 15(9), pp. 370-374. Available at: https://www.ncbi.nlm.nih.gov/pubmed/16178206/ (Accessed: 26 March 2017).

Chand, M. and Dabbas. N. (2007) 'Nil by mouth: a misleading statement', Journal of Perioperative Practice, 17(8), pp. 366-371. https://www.ncbi.nlm.nih.gov/pubmed/17867424 (Accessed: 26 March 2017).

Childs, S., Blenkinsopp, E., Hall, A. and Walton, G. (2005) 'Effective e-learning for health professionals and students - barriers and their solutions. A systematic review of the literature - findings from the HeXL project', Health Information Library Journal, 22(2), pp. 20-32. https://doi.org/10.1111/j.1470-3327.2005.00614.x 
Cochrane, T. (2007) 'Developing interactive multimedia learning objects using QuickTime', Computers in Human Behaviour, 23(6), pp. 2596-2640. http://dx.doi.org/10.1016/j.chb.2006.08.007

Conceição, S., Olgren, C. and Ploetz, P. (2006) 'Reusing learning objects in three settings: implications for online instruction', International Journal of Instructional Technology and Distance Learning, 3(4), pp. 3-14. Available at: http://www.itdl.org/Journal/April_06/article01.htm (Accessed: 26 March 2017).

Costelloe, E., Sherry, E. and Magee, P. (2009) ‘Experiences gained using a set of SCORM compliant reusable learning objects for teaching programming', International Journal on E-Learning, 8(2), pp. 175-191.

Crenshaw, J. T. and Winslow, E. H. (2008) 'Preoperative fasting duration and medication instruction: are we improving?', Association of Perioperative Registered Nurses (AORN) Journal, 88(6), pp. 963-973. http://dx.doi.org/10.1016/j.aorn.2008.07.017

Farha, N.W. (2009) 'An exploratory study into the efficacy of learning objects', The Journal of Educators Online, 6(2), pp. 1-32. Available at: https://www.thejeo.com/archive/archive/2009_62/farhapaperpdf (Accessed: 26 March 2017).

Gauss, B. and Urbas, L. (2003) 'Individual differences in navigation between sharable content objects - an evaluation study of a learning module prototype', British Journal of Educational Technology, 34(4), pp. 499-509. http://dx.doi.org/10.1111/1467-8535.00346

Gee, B. M., Moholy, K., Lloyd, K. and Seikal, A. (2015) 'Field-testing reusable learning objects related to sensory over-responsiveness', The Open Journal of Occupational Therapy, 3(2), pp. 1-21. http://dx.doi.org/10.15453/2168-6408.1152

Ghoncheh, R., Kerkhof, A. J. F. M. and Koot, H. M. (2014) 'Effectiveness of adolescent suicide prevention e-learning modules that aim to improve knowledge and self- 
confidence of gatekeepers: study protocol for a randomized controlled trial', Trials Journal, 15(52), pp. 1-7. http://dx.doi.org/10.1186/1745-6215-15-52

Halverson, R., Wolfenstein, M., Williams, C. C. and Rockman, C. (2009) 'Remembering math: the design of digital learning objects to spark professional learning', ELearning, 6(1), pp. 97-118. http://dx.doi.org/10.2304/elea.2009.6.1.97. Available at: http://dm.education.wisc.edu/rrhalverson/intellcont/Remembering\%20Math\%20ELearning-1.pdf (Accessed 26 March 2017).

Honey, P. and Mumford, A. (2000) The learning styles helper's guide. Maidenhead: Peter Honey Publications Ltd.

Hughes, S. J. and Quinn, F. M. (2013) Quinn's principles and practice of nurse education. $6^{\text {th }}$ edn. Andover: Cengage Learning.

Johnson, N., List-Ivankovic, J., Eboh, W. O., Ireland, J., Adams, D., Mowatt, E. and Martindale, S. (2010) 'Research and evidence based practice: using a blended learning approach to teaching and learning in undergraduate nurse education', Nurse Education in Practice, 10(1), pp. 43-47. http://dx.doi.org/10.1016/j.nepr.2009.03.012

Kolb, D.A. (1984) Experiential learning: experience as the source of learning and development. New Jersey: Prentice-Hall.

Lymn, J. S., Bath-Hextall, F. and Wharrad, H.J. (2008) 'Pharmacology education for nurse prescribing students - a lesson in reusable learning objects', BMC Nursing, 7(2), pp. 1-11. http://dx.doi.org/10.1186/1472-6955-7-2

MacDonald, C. J., Stodel, E., Thompson, T. L., Muirhead, B., Hinton, C., Carson, B. and Banit, E. (2005) 'Addressing the eLearning contradiction: a collaborative approach for developing a conceptual framework learning object', Interdisciplinary Journal of Knowledge and Learning Objects, 1, pp. 79-98. Available at: http://trove.nla.gov.au/work/77230123?q\&versionld=90453683 (Accessed: 26 March 2017). 
Macnee, C.L. and McCabe, S. (2008) Understanding nursing research: reading and using research in evidence-based practice. $2^{\text {nd }}$ edn. Philadelphia: Lippincott Williams and Wilkins.

McCutcheon, K., Lohan, M., Traynor, M. and Martin, D. (2015) 'A systematic review evaluating the impact of online or blended learning vs. face-to-face learning of clinical skills in undergraduate nurse education', Journal of Advanced Nursing, 71(2), pp. 255-270. http://dx.doi.org/10.1111/jan.12509

McVicar, A., Andrew, S. and Kemble, R. (2014) 'Biosciences within the pre-registration (pre-requisite) curriculum: an integrative literature review of curriculum interventions 1990-2012', Nurse Education Today, 34(4), pp. 560-568. http://dx.doi.org/10.1016/j.nedt.2013.08.012

Melnyk, B. M. and Fineout-Overholt, E. (2011) Evidence-based practice in nursing \& healthcare: a guide to best practice. $2^{\text {nd }}$ edn. London: Lippincott Williams and Wilkins.

Meyer, J. H. F. and Land, R. (2005) 'Threshold concepts and troublesome knowledge (2): epistemological considerations and a conceptual framework for teaching and learning', The International Journal of Higher Education Research, 49(3), pp. 373388. http://dx.doi.org/10.1007/s10734-004-6779-5

Moeller, B. and Rietzes, T. (2011) Integrating technology with student-centred learning. Quincy: Nellie Mae Education Foundation. Available at: http://www.nmefoundation.org/getmedia/befa9751-d8ad-47e9-949dbd649f7c0044/Integrating-Technology-with-Student-Centered-Learning?ext=.pdf (Accessed 20 June 2016).

Rebar, C. R., Gersch, C. J., Macnee, C. L. and McCabe, S. (2011) Understanding nursing research: using research in evidence-based practice. $3^{\text {rd }}$ edn. Philadelphia: Lippincott Williams and Wilkins. 
Rigby, L., Wilson, I., Baker, J., Walton, T., Price, O., Dunne, K. and Keeley, P. (2012) 'The development and evaluation of a 'blended' enquiry based learning model for mental health nursing students: "making your experience count"', Nurse Education Today, 32(3), pp. 303-308. http://dx.doi.org/10.1016/j.nedt.2011.02.009

Roberts, S. (2013) 'Preoperative fasting: a clinical audit', Journal of Perioperative Practice, 23(1), pp. 11-16.

Royal College of Nursing (RCN) (2005) Perioperative fasting in adults and children: an RCN guideline for the multidisciplinary team. London: Royal College of Nursing. Available at: https://www.rcn.org.uk/professional-development/publications/pub002800 (Accessed: 26 March 2017).

Ruiz, J. G., Mintzer, M. J. and Issenberg, S. B. (2006) 'Learning objects in medical education', Medical Teacher, 28(7), pp. 599-605. http://dx.doi.org/10.1080/01421590601039893

Sun, Q. and Ganesh, G. (2014) 'Developing and teaching an online MBA marketing research class: implications for online learning effectiveness', Journal of Education for Business, 89(7), pp. 337-345. http://dx.doi.org/10.1080/08832323.2013.806885

Sung, Y. H., Kwon, I. G. and Ryu, E. (2008) 'Blended learning on medication administration for new nurses: integration of e-learning and face-to-face instruction in the classroom', Nurse Education Today, 28(8), pp. 943-952. http://dx.doi.org/10.1016/j.nedt.2008.05.007

Sutton, P. A. and Smith, L. V. (2008) 'Pre-operative nausea and vomiting (PrONV)', The Internet Journal of Anethesiology, 16(2), pp.1-3 [Online]. Available at: http://print.ispub.com/api/0/ispub-article/11245 (Accessed 20 June 2016).

Wakefield, A. B., Carlisle, C. Hall, A. G. and Attree, M. J. (2008) 'The expectations and experiences of blended learning approaches to patient safety education', Nurse Education in Practice, 8(1), pp. 54-61. http://dx.doi.org/10.1016/j.nepr.2007.04.007 
Wharrad, H. J., and Windle, R. (2010) 'Case studies of creating reusable inter-professional e-learning objects', in Bromage, A., Coulder, L., Thistlethwaite, J. and Gordon, F. (eds) Interprofessional e-learning and collaborative work: practices and technologies. PA, USA: IGI-Global Publishing, pp. 260-274.

Williams, J., O'Connor, M., Windle, R. and Wharrad, H.J. (2015) 'Using reusable learning objects (rlos) in injection skills teaching: evaluations from multiple user types', Nurse Education Today, 35(12), pp. 1275-1282. http://dx.doi.org/10.1016/j.nedt.2015.06.001

Windle, R. J., Wharrad, H., McCormick, D., Laverty, H. and Taylor, M. G. (2010) 'Sharing and reuse in OER: experiences gained from open reusable learning objects in health', Journal of Interactive Media in Education, 1 [Online]. http://doi.org/10.5334/2010-4

Windle, R. and Wharrad, H. J. (2010) 'Reusable learning objects in health care education', in Bromage, A., Coulder, L., Thistlethwaite, J. and Gordon, F. (eds) Interprofessional e-learning and collaborative work: practices and technologies. PA, USA: IGI-Global Publishing, pp. 244-259. https://doi.org/10.4018/978-1-61520-889$\underline{0 . \operatorname{ch} 020}$

\section{Author details}

Stuart Roberts is a Principal Lecturer in the Faculty of Health, Psychology and Social Care at the Manchester Metropolitan University.

Richard Windle is a Senior Lecturer in the Faculty of Medicine and Health Sciences at the University of Nottingham. 